УДК 323, 327

\title{
Елена АНАНЬЕВА
}

\section{“СТРАННЫЕ ВЫБОРЫ” В БРИТАНИИ}

\begin{abstract}
Аннотация. В статье исследованы досрочные всеобщие выборы в Британии (декабрь 2019 г.), факторы, которые их спровоцировали, а также причины и последствия результатов голосования для британской политической жизни. Автор отмечает, что патовая ситуация в парламенте Британии, в котором противостояние исполнительной и законодательной ветвей власти не позволяло решить вопрос о выходе страны из ЕС, стала причиной неизбежных досрочных выборов 2019 г. В статье представлен анализ позиций политических партий в отношении брекзита и хода предвыборной кампании, а также исследованы итоги выборов. Сделан вывод, что победе Консервативной партии способствовала мажоритарная избирательная система и усталость избирателей от неопределенности. Новая расстановка политических сил после выборов сделала правительство стабильным, а брекзит неотвратимым. Однако раскол в обществе не преодолен, а Британии предстоит вести сложные переговоры о будущих отношениях с Европейским союзом.
\end{abstract}

Ключевые слова: Британия, парламентские выборы, Консервативная партия, Лейбористская партия, Партия либеральных демократов, Шотландская национальная партия, партия “Брекзит”.

Анализируя итоги досрочных выборов в Британии, обозреватели подчёркивают бесспорную победу Консервативной партии. Тем не менее, распределение голосов избирателей свидетельствует о том, что настроения в британском обществе неоднозначны.

12 декабря 2019 г. Британия провела уже вторые досрочные выборы. Первые внеочередные выборы объявила в 2017 г. Тереза Мэй, надеясь укрепить шаткое большинство своей партии в парламенте в преддверии переговоров с Брюсселем по брекзиту. Результат оказался для правящей партии негативным: консерваторы (при 42,3\% голосов и 317 местах) утратили большинство в Палате общин и вынуждены были заключить соглашение с Демократической юнионистской партией (ДЮП) из

(C) Ананьева Елена Владимировна - кандидат философских наук, руководитель Центра британских исследований Института Европы РАН. Адрес: 125009, Россия, Москва, д. 11, стр. 3.E-mail: e-ananieva@yandex.ru

DOI: http://dx.doi.org/10.15211/soveurope620197684 
Северной Ирландии о поддержке (confidence-and-supply) в парламенте, что не предполагало формирования полноценной коалиции. Тем не менее, ДЮП, обладая лишь 10 мандатами, получила несоразмерный политический вес.

\section{Неизбежность досрочных выборов}

В течение трёх лет правления Т. Мэй Консервативная партия вступила в глубокий кризис, раздираемая острыми разногласиями по брекзиту: ушли в отставку 36 членов правительства, добровольно или принудительно; коллективная ответственность правительства перестала существовать.

В Вестминстере прежнее размежевание на правых и левых уступило делению на брекзитеров и бремейнеров. В парламентских фракциях консерваторов и лейбористов партийная дисциплина была нарушена (голосование против “генеральной линии" своей партии уже никого не удивляло и, более того, лидеры партий не осмеливались налагать взыскания на “бунтовщиков”). Ранее никогда не было столь большого количества депутатов, которые бы вышли из своих партий, как за два с небольшим года полномочий парламента 57-го созыва, причём в основном из-за разногласий с партийным руководством по брекзиту. В феврале 2019 г. восемь лейбористов и три консерватора покинули свои партии, ещё более 20 депутатов-тори перешли на скамьи независимых парламентариев. Семь депутатов (как консерваторов, так и лейбористов) присоединились к либерал-демократам, что увеличило их фракцию до 20 человек.

Общественность не оставалась в стороне - демонстрации за и против брекзита проходили по всей стране. Мирным противостояние назвать нельзя: члены Палаты общин получали не только оскорбления, но и угрозы физической расправы. В самом Вестминстере депутаты договорились воздержаться от непарламентских выражений лишь в сентябре 2019 г.

Тереза Мэй даже с третьей попытки не смогла преодолеть противодействие парламента и добиться одобрения своего Соглашения с ЕС, заключённого в ноябре 2018 г. Итоги выборов в Европейский парламент в мае 2019 г. и опросы общественного мнения показывали, что избиратели консерваторов в массовом порядке отдавали предпочтение партии Н. Фараджа “Брекзит”. Тереза Мэй была вынуждена уйти в отставку.

Консерваторам, чтобы остановить отток сторонников и вернуть их симпатии, необходимо было избрать лидера, который выступал за жёсткий брекзит [Капитонова, 2019]. Им стал Борис Джонсон, который пользуется поддержкой рядовых членов партии, поскольку однозначно поддерживает выход Британии из ЕС. Более того, он намеревался вывести Британию из Евросоюза в обозначенный срок 31 октября 2019 г. со сделкой или без сделки.

Смена премьер-министра не только не разрешила ситуацию, но противостояние исполнительной, законодательной и судебной власти в Британии достигло апогея. Б. Джонсон объявил о приостановлении работы парламента с 9 сентября по 14 октября. Формально ничего незаконного в его решении не было (срок не ограничен). Однако перерыв должен был продлиться долгих пять недель. Смысл данной меры не позволить парламенту воспрепятствовать брекзиту. По убеждению премьера угроза выхода Британии из ЕС без соглашения с Брюсселем представляла собой

$$
\text { Современная Европа, 2019, №6 }
$$


крепкую переговорную позицию, чтобы заставить Евросоюз пойти на уступки по “бэкстопу” - режиму границы между Республикой Ирландия и Северной Ирландией [Бабынина, 2019] ${ }^{1}$.

Депутаты были возмущены намерением нового премьер-министра исключить их из политического процесса в судьбоносный для страны момент и заранее приняли контрмеры. Палата общин одобрила внесение в повестку дня законопроекта лейбориста Хиллари Бенна о запрете на выход Британии из ЕС без сделки и об отсрочке брекзита до 31 января 2020 г. (328: 301), то есть голосами не только оппозиции, но и двух десятков парламентариев-консерваторов. Б. Джонсон, стремясь укрепить партийную дисциплину, исключил их из партии (фракция сократилась до 288 депутатов). Второе поражение Б. Джонсон потерпел 9 сентября, когда Палата общин приняла Закон Бенна (327:299). Премьер-министр внёс законопроект о досрочных парламентских выборах 15 октября, но и на этот раз потерпел поражение: депутаты не хотели, чтобы Джонсон мог провести выборы до объявленной даты выхода Британии из ЕС (31 октября).

17 октября Лондон и Брюссель объявили о том, что договорились о новой сделке: главное возражение брекзитеров против соглашения “в редакции Мэй” было снято - так называемый "бэкстоп" . Неудивительно, что ДЮП отказалась поддержать соглашение с ЕС “в редакции Джонсона"з.

Закон Бенна обязывал Б. Джонсона направить в Брюссель просьбу об отсрочке брекзита, что формально премьер-министр и сделал (ранее дав подобное обещание

${ }^{1}$ Соглашение, подписанное Терезой Мэй в ноябре 2018 г., предусматривало сохранение открытой границы между Ирландией и Северной Ирландией (по Белфастскому соглашению 1998 г.). Основной посыл ДЮП: единый статус должен распространяться на всю территорию Великобритании. Условия соглашения вызывали недовольство как брекзитеров, так и бремейнеров. Первые были недовольны тем, Великобритания не имела бы права заключать торговые соглашения с третьими странами, оставаясь в юрисдикции Суда ЕС, причём неопределённое время. Бремейнеры задавались вопросом: зачем тогда вообще выходить из ЕС, лишаясь права голоса в его руководящих органах?

${ }^{2}$ Новое Соглашение, которое заключил премьер-министр Б. Джонсон 19 октября, предусматривает особый режим на территории Северной Ирландии, фактически устанавливая границу по Ирландскому морю. Таможенный контроль должен быть установлен в морских портах и аэропортах Северной Ирландии, где по некоторым аспектам сохранятся правила Единого рынка. Джонсон уступил Брюсселю и по политическим аспектам в Северной Ирландии. ДЮП предвидит, что по прошествии времени регион разойдется с Великобританией в регулировании экономических вопросов, и произойдет “ползучая аннексия” Ольстера Ирландией.

${ }^{3}$ Agreement on the withdrawal of the United Kingdom of Great Britain and Northern Ireland from the European Union and the European Atomic Energy Community. 19.10.2019; Declaration by Her Majesty's Government of the United Kingdom of Great Britain and Northern Ireland concerning the operation of the 'Democratic consent in Northern Ireland' provision of the Protocol on Ireland/Northern Ireland. 19.10.2019; Political Declaration setting out the framework for the future relationship between the European Union and the United Kingdom. 19.10.2019; Statement that political agreement has been reached and that the United Kingdom has concluded an agreement with the European Union under Article 50(2) of the Treaty on European Union. 19.10.2019.

Современная Европа, 2019, №6 
суду), но так, чтобы выхолостить его суть. Он направил фотокопию положения закона с текстом просьбы без своей подписи, сопроводив письмом уже за своей подписью о нецелесообразности переноса даты брекзита.

Точно так же и депутаты использовали юридическое крючкотворство, отказавшись голосовать по соглашению с ЕС, достигнутому Б. Джонсоном. Тем не менее, они приняли во втором чтении законопроект о выходе Британии из ЕС, в который данное соглашение инкорпорировано, как и процедура его применения. Казалось бы, победа для главы правительства - Мэй не смогла продвинуться столь далеко, однако отказ парламента от ускоренного трёхдневного обсуждения объёмного законопроекта (как того хотел Джонсон) подорвали саму цель и обещание премьерминистра - вывести Британию из Евросоюза 31 октября “во что бы то ни стало". Поспешность Джонсона объяснялась и тем, что бремейнеры могли вносить в законопроект опасные для брекзитеров поправки.

При данной “арифметике” в парламенте премьер-министр не мог провести через него ни один свой законопроект. Лишь с четвёртой попытки, 29 октября Палата общин проголосовала за досрочные выборы 12 декабря, предотвратив брекзит без сделки, проведение выборов до даты выхода из ЕС 31 октября и добившись отсрочки выхода Британии из ЕС до 31 января 2020 г. Аргументы оппозиции против выборов были исчерпаны.

\section{Предвыборная кампания}

В преддверии выборов острый характер стала носить не только межпартийная борьба: две ведущие партии, будучи “зонтичными” (мажоритарная система способствует крупным партиям) ввиду разногласий по брекзиту не отличались единством.

Однако если в партии тори верх одержали брекзитеры, то в партии лейбористов стремление руководства удержать предпочтения избирателей и из числа брекзитеров, и из рядов бремейнеров создавало впечатление двойственности позиции (новые переговоры с ЕС, второй референдум при нейтральной позиции лидера партии Дж. Корбина).

Чёткие позиции по членству в ЕС были характерны для малых игроков - партии "Брекзит" (однозначно за жёсткий развод с Брюсселем), Партии либеральных демократов (отзыв уведомления о выходе Британии из ЕС при отказе проводить второй референдум) и Шотландской национальной партии (за членство в ЕС).

Отсюда следует логика предвыборных союзов или межпартийное соперничество идейно близких акторов в угоду узкопартийным интересам. Перед выборами в Европарламент в мае 2019 г. партии не стали заключать соглашения (снимать кандидатов в пользу друг друга). Учитывая вероятность брекзита, очевидно, все участники не придавали им серьёзного значения, а при пропорциональной системе голосования на этих выборах они могли составить представление о своём политическом весе. Между тем распределение голосов избирателей свидетельствовало: ни партии бремейнеров, ни партии брекзитеров не получили явного преимущества, если суммировать доли голосов за каждую из сторон.

Однако всеобщие парламентские выборы по мажоритарной системе меняют политическое поведение избирателей, и исходя из представления о нём, партии подбирают и методы предвыборной кампании. Свою роль играют долгосрочные соци-

Современная Европа, 2019, №6 
ально-экономические изменения и краткосрочные политические факторы. Так, к долгосрочным изменениям относятся: организационная деградация партий и снижение их численности (для левых партий имеет существенное значение упадок профсоюзов); повышение уровня образования электората (их интересы защищают адвокаты, а не профсоюзы и партии); общее разочарование и недоверие граждан к политической системе. Классовый признак для приверженности к какой-либо партии утратил значение (в 1960-х гг. 8 из 10, а к 2010 г. - лишь 6 из 10 избирателей ассоциировали себя с одной из двух ведущих партий). Постепенно возрастала роль малых партий - тенденция, прерванная лишь в 2017 г. Предпочтения избирателей стали изменчивее: в период 2010-2017 гг. лишь половина из них голосовала за одну и ту же партию на выборах. Волатильность объясняется “электоральными шоками” (например, финансово-экономический кризис 2008 г., обострение проблемы иммиграции). Таковым стал и брекзит ${ }^{1}$.

Более того, политики агитировали голосовать за противников “своих" партий: Т. Блэр (бывший премьер-министр от ЛПВ) призвал не допустить получения большинства консерваторами или лейбористами; Дж. Мэйджор (экс-премьер-министр от консерваторов) - призвал голосовать за тех бывших тори, кого Джонсон исключил из партии и кто выставил свои кандидатуры уже в качестве независимых; М. Хезелтайн, бывший министр при М. Тэтчер, предпочёл голосовать за либералдемократов. В этой точке долгосрочные тенденции пересекаются с краткосрочными факторами. Подобный отказ от партийной лояльности на разных этажах социальной лестницы и дал повод политическому обозревателю Би-би-си Лауре Кюнсберг охарактеризовать выборы как "странные"2.

Малые партии бремейнеров всё же сформировали предвыборные блоки (ПЛД, “Зелёные”, Плайд Кумри), договорившись не выставлять кандидатов друг против друга.

Н. Фарадж в свою очередь безрезультатно предлагал Б. Джонсону союз. Без политической игры не обошлось: сначала Фарадж был намерен выставить против консерваторов своего кандидата в каждом округе, но впоследствии узкопартийным задачам предпочёл общий интерес брекзитеров. Чтобы не разбивать голоса избирателей-брекзитеров, он снял кандидатов от партии "Брекзит" в тех округах, где в 2017 г. победил консерватор, оставив их в округах, где в 2017 г. победил лейборист, но на референдуме 2016 г. округ голосовал за брекзит. Фарадж ставил своей задачей привлечь голоса сторонников лейбористов, которые поддерживали брекзит, но не хотели, проголосовав за консерваторов, увидеть Б. Джонсона в качестве премьер-министра.

\footnotetext{
${ }^{1}$ Press release: Most volatile British electorate in modern times. The British Election Study Team. 08.10.2019. URL: https://www.britishelectionstudy.com/bes-resources/press-release-mostvolatile-british-electorate-in-modern-times/\#.XfUiZ3duK70; Surridge P. How Britain's elections became impossible to predict. URL:

https://www.theguardian.com/commentisfree/2019/nov/06/britain-election-brexit-voters.

${ }^{2}$ Weston K. BBC's Laura Kuenssberg dismantles Lord Heseltine's 'confident' Lib Dem election claim. The Express. 26.11.2019. URL: https://www.express.co.uk/news/uk/1209366/BBC-NewsLaura-Kuenssberg-general-election-Lord-Heseltine-radio-4-today-live-UK
} 
Выборы в Палату общин проводятся по мажоритарной системе, избирают 650 депутатов. При явке в 67,3\% выборы принесли убедительную победу Консервативной партии - 43,4\% голосов, 56\% мест (365 мандатов) ${ }^{1}$, разгром Лейбористской партии (ЛПВ) - 32,3\% голосов и $31 \%$ мест (203 мандата), победу Шотландской национальной партии (ШНП) - 3,9\% голосов и 7\% мест (48 мандатов) ${ }^{2}$.

Выборы ознаменовали сомнительный прогресс Партии либерал-демократов (ПЛД) - партия не смогла существенно нарастить политический вес $(11,4 \%$ голосов и 1,7\% мест (11 мандатов)), вопреки своим надеждам, а её лидер Джо Суинсон даже проиграла в своём избирательном округе, причём кандидату от ШНП. Партия “Брекзит" Н. Фараджа не прошла в парламент.

ШНП получила солидную прибавку мест по сравнению с выборами 2017 года (48 против 35), расценив свою победу как мандат на повторный референдум о независимости Шотландии. Другой вопрос - что ШНП должна получить согласие центрального правительства и обеих палат парламента на референдум, а при Джонсоне в качестве премьер-министра и консервативном большинстве в Палате общин это вряд ли возможно.

Примечательно, что Демократическая юнионистская партия (ДЮП), которая после выборов 2017 г. заключила с Консервативной партией соглашение о поддержке (confidence-and-supply), потеряла 2 места. В результате впервые партии ирландских националистов получили больше мест в Вестминстере, чем ольстерские юнионисты (хотя партия Шинн Фейн, участвуя в выборах, бойкотирует работу в британском парламенте).

Напомним, что полгода назад на выборах в Европейский парламент (май 2019 г.), которые проводятся по пропорциональной системе, партия "Брекзит" выиграла с оглушительным успехом (29 из квоты Британии в 75 депутатов). "Проевропейская" ПЛД (16 мест) показала лучший результат за всю свою историю, преодолев скепсис избирателей. ЛПВ (10 мест) утратила $11,3 \%$ голосов ввиду половинчатости своей позиции по брекзиту. Даже “Зелёные” (7 мест) обошли консерваторов. Правящая партия тори при Т. Мэй в качестве её лидера и премьер-министра потерпела тогда сокрушительное поражение, заняв 5-е место (4 депутата). ШНП (3 места) прибавила 1\% голосов против 2014 г.

\section{Изменчивость политической фортуны: причины победы Консервативной партии}

В Британии голосуют за партии, а не за их лидеров, хотя фактор персонификации нельзя сбрасывать со счетов, особенно при столь полярных личностях, как Джонсон и Корбин, и программах их партий. Рейтинги лидеров всех партий оставались в отрицательной зоне, хотя Джонсон опережал Корбина (33:22), как и Консервативная партия - лейбористов практически по всем параметрам. Волатильность политических предпочтений избирателей сыграла свою роль: четверть опрошенных

${ }^{1}$ В 2017 г. Консервативная партия при 43\% голосов получила 49\% мест (317).

${ }^{2}$ ШНП выставляет кандидатов только в Шотландии; квота региона в общенациональном парламенте составляет 59 мест. UK results: Conservatives win majority. URL: https://www.bbc.com/news/election/2019/results. 
заявили, что могут поменять свои политические предпочтения в последний момент $^{1}$.

Действительно, избиратели предпочли тактическое голосование: рейтинг лейбористов по опросам общественного мнения постепенно повышался за счёт ПЛД, а рейтинг консерваторов - за счёт партии "Брекзит”. Однако разрыв между ведущими партиями оставался примерно тем же - на 10 процентных пунктов он был выше у тори. Сторонники партии “Брекзит” голосовали за консерваторов, а голоса бремейнеров оказались разбиты между не договорившимися лейбористами и либералдемократами и даже частично отошли консерваторам.

ЛПВ и ПЛД не стали заключать предвыборный пакт, а ПЛД особенно была недовольна лидером ЛПВ ДЖ. Корбином, которого она (и не только она) считала “слишком левым”. Лейбористы намеревались в случае прихода к власти вновь провести переговоры с ЕС о новом соглашении, а затем провести по нему новый референдум, включив в бюллетень и такой вариант ответа, как “остаться в ЕС”. Сам Дж. Корбин заявил, что сохранит нейтральную позицию в отношении референдума. Подобный сложный курс был продиктован попыткой “усидеть на двух стульях" сохранить сторонников как среди брекзитеров, так и бремейнеров.

Либерал-демократы однозначно высказались за отзыв уведомления о выходе Британии из ЕС, даже не предложив избирателям снова высказаться на втором референдуме. В результате эти партии серьёзно проиграли, причём лейбористы уступили консерваторам даже в своих надёжных, рабочих избирательных округах. В этих округах, высказавшихся на референдуме 2016 г. за выход из ЕС, голосов за ЛПВ было подано на 10\% меньше, а в округах, голосовавших за членство в ЕС, - на $6 \%{ }^{2}$. Как писали аналитики, Джонсон “пробил красную стену” (красный - цвет традиционных избирательных округов ЛПВ на севере Англии). Лидеры ЛПВ и ПЛД (Дж. Корбин и Джо Суинсон) должны будут уйти в отставку. Недаром Н. Фарадж заявил, что он “убил либерал-демократов и серьёзно ранил лейбористов"3.

Если сравнить доли голосов бремейнеров и брекзитеров (на основе предвыборных манифестов партий), то получится, что ЛПВ, ПЛД, ШНП, Плайд Камри и “Зелёные” завоевали поддержку 52,1\% избирателей, а Партии тори и “Брекзит” $46,8 \%{ }^{4}$. Избиратели-брекзитеры были более равномерно распределены по округам, голосовавшим на референдуме 2016 г. за выход из ЕС, в то время как избиратели-

\footnotetext{
${ }^{1}$ Ipsos-MORI. NHS surges to match Brexit in final Issues Index ahead of the 2019 General Election. 09.12.2019. URL: https://www.ipsos.com/ipsos-mori/en-uk/nhs-surges-match-brexit-final-issuesindex-ahead-2019-general-election; Conservatives hold 12-point lead over Labour heading into final week of the election campaign. URL: https://www.ipsos.com/ipsos-mori/en-uk/conservativeshold-12-point-lead-over-labour-heading-final-week-election-campaign. 06.12.2019.

${ }^{2}$ Read C. John Curtice reveals why the Tories stormed to victory - and what Labour did wrong. https://www.express.co.uk/news/politics/1217015/john-curtice-general-election-2019-resultstories-labour-jeremy-corbyn-heartlands. The Express. 13.12.2019.

${ }^{3}$ General election 2019: 'I killed the Liberal Democrats and hurt Labour', says Farage. URL: https://www.bbc.com/news/av/uk-politics-50765372/general-election-2019-i-killed-the-liberaldemocrats-and-hurt-labour-says-farage.

${ }^{4}$ Fisher S. How did the Conservatives win?_URL: https://www.prospectmagazine.co.uk/politics/howdid-the-conservatives-win-boris-johnson-election-voting-polling-numbers.
} 
бремейнеры больше сконцентрированы в округах, голосовавших за членство Британии в ЕС. Причина победы Джонсона, таким образом, заключается не только в разобщённости партий бремейнеров, но и в географическом распределении их сторонников по избирательным округам, то есть в издержках мажоритарной системы.

Многие в Британии считают, что решение выйти из ЕС было неверным, что правительство плохо справляется этой задачей ${ }^{1}$, но и усталость от затянувшейся неопределённости существенно повлияла на исход всеобщих выборов 2019 года. Неудивительно, что лозунг Джонсона “Завершим брекзит!” (Get Brexit Done!) нашёл отклик у электората. Однако вряд ли можно согласиться с выводом Т.Н. Андреевой, что курс на брекзит “оказался созвучен желаниям большинства населения страны" [Андреева, 2019].

Итак, после трёх всеобщих выборов в течение пяти лет (2015, 2017 и 2019 гг.) в Британии утвердится правительство на полный легислатурный срок. Б. Джонсон получил мандат на завершение брекзита - 9 января 2020 г. Палата общин приняла Закон о выходе из ЕС в третьем чтении, и Британия выйдет из европейской интеграции 31 января 2020 г.

Однако затем между Лондоном и Брюсселем последуют переговоры о будущих отношениях, которые неизбежно станут тяжёлыми и длительными, хотя Джонсон обещает, что они будут лёгкими и непродолжительными. Конечно, Джонсон заявляет, что Соединённое Королевство выйдет из переговоров с ЕС по поводу будущих отношений, чем бы они ни завершились (то есть брекзит “без сделки” вернётся в повестку дня). Между тем британские эксперты и политические деятели предупреждают, что торговые переговоры могут идти десятилетие, и правительство может снова войти в политический кризис. Даже если избиратели разочаруются в брекзите, новый референдум исключён, и протесты против политики правительства будут проходить в основном вне стен парламента.

Британцы, считает бывший постпред Соединённого Королевства при ЕС Айван Роджерс, почувствуют бремя “вечного брекзита" (Brexiternity), который превратится в "день сурка"

\section{Список литературы}

Ананьева Е.В.(ред.) (2019) Итоги правления Терезы Мэй, ДИЕ РАН, №364, Москва, Россия, 148 с.

Андреева Т.Н. (2019) Внеочередные парламентские выборы в Британии как ещё один референдум по вопросу о выходе страны из EC. URL:

https://www.imemo.ru/index.php?page_id=502\&id=5536\&ret=527

\footnotetext{
${ }^{1}$ YouGov. Political trackers (5-6 Dec update). URL: https://yougov.co.uk/topics/politics/articlesreports/2019/12/08/political-trackers-5-6-dec-update.

${ }^{2}$ Rogers I. The biggest crisis of Brexit to date actually still lies ahead of us in late 2020. Prospect Magazine. 25 November 2019. URL: https://www.prospectmagazine.co.uk/politics/ivan-rogerson-brexit-the-worst-is-yet-to-come-eu-trade-deal-boris-johnson-labour-election-speech-glasgow.
} 
Бабынина Л. (2019) Брекзит: провал ратификации в Палате общин. Европейский союз: факты и комментарии. Выпуск 95. C. 72-76. URL: http://www.edcaes.ru/data/edcaes/content/user_files/files/95.pdf

Капитонова Н.К. (2019) Партия тори в поисках нового лидера. Итоги правления Терезы Мэй, ДИЕ РАН, №364, Москва, Россия, С. 45-54.

\section{References}

Ananieva E. (ed.) (2019) Itogi pravlenija Terezy Mjej [Theresa May's Governance - Summing Up]. Reports of the Institute of Europe, no. 364, Moscow, Russia, 148 p.

Andreeva T.N. (2019) Vneocherednye parlamentskie vybory v Britanii kak eshche odin refe-rendum po voprosu o vyhode strany iz https://www.imemo.ru/index.php?page_id=502\&id=5536\&ret=527

Babynina L. (2019) Brekzit: proval ratifikacii v Palate obshchin. Evropejskij soyuz: fak-ty i kommentarii. Vypusk 95. S. 72-76, available at: http://www.edc-aes.ru/data/edcaes/content/user_files/files/95.pdf

Kapitonova N.K. (2019) Partiya tori v poiskah novogo lidera. Itogi pravleniya Terezy Mej, DIE RAN, №364, Moskva, Rossiya, S. 45-54.

Curtis Ch., McDonnell A. "How Britain Voted in the 2019 General Election", available at: https://yougov.co.uk/topics/politics/articles-reports/2019/12/17/how-britain-voted-2019-general-election.

Rogers I. "The Biggest Crisis of Brexit to Date Actually Still Lies Ahead of us in Late 2020. Prospect Magazine. 25 November 2019", available at: https://www.prospectmagazine.co.uk/politics/ivan-rogers-onbrexit-the-worst-is-yet-to-come-eu-trade-deal-boris-johnson-labour-election-speech-glasgow.

Surridge P. "How Britain's Elections Became Impossible to Predict. The Guardian", available at: https://www.theguardian.com/commentisfree/2019/nov/06/britain-election-brexit-voters.

\section{"Strange" Elections in the UK}

Author: Ananieva E., Doctor of Sciences (Philosophy), Head of the UK Studies Center, Institute of Europe RAS. Address: 11-3, Mokhovaya str., Moscow, Russia, 125009. E-mail: e-ananieva@yandex.ru

Abstract. The article provides insight into the UK snap election (December, 2019), the reasons why it was called, the factors which shaped the outcomes and their consequences for British political life. The author argues that the deadlock in Westminster, where the juxtaposition of the executive and legislative branches of power precluded solving the issue of Brexit triggered unavoidable snap elections-2019. The article examines the UK political parties' position on Brexit and their electoral campaigns. The paper concludes that the victory of the Conservative party was due to the first-past-the-post system and to the exhaustion of the electorate of uncertainty. The new configuration of political forces brought into office a stable government and made Brexit inevitable. Still the country is divided, and Britain must conduct complicated talks with Brussels on future relations. The author also made a conclusion that even if the electors will be disappointed by Brexit the new referendum is impossible and the manifestations against the policy of the government will be generally out of the Parliament walls.

Key words: UK, general elections, Conservative Party, Labour Party, Liberal Democrats, Scottish National Party, Brexit party.

DOI: http://dx.doi.org/10.15211/soveurope620197684 